\title{
TU/e EmonONEN

\section{Electronic memory effects in diodes from a zinc oxide nanoparticle-polystyrene hybrid material}

\section{Citation for published version (APA):}

Verbakel, F., Meskers, S. C. J., \& Janssen, R. A. J. (2006). Electronic memory effects in diodes from a zinc oxide nanoparticle-polystyrene hybrid material. Applied Physics Letters, 89(10), 102103-1/3. [102103]. https://doi.org/10.1063/1.2345612

DOI:

$10.1063 / 1.2345612$

Document status and date:

Published: 01/01/2006

\section{Document Version:}

Publisher's PDF, also known as Version of Record (includes final page, issue and volume numbers)

\section{Please check the document version of this publication:}

- A submitted manuscript is the version of the article upon submission and before peer-review. There can be important differences between the submitted version and the official published version of record. People interested in the research are advised to contact the author for the final version of the publication, or visit the $\mathrm{DOI}$ to the publisher's website.

- The final author version and the galley proof are versions of the publication after peer review.

- The final published version features the final layout of the paper including the volume, issue and page numbers.

Link to publication

\section{General rights}

Copyright and moral rights for the publications made accessible in the public portal are retained by the authors and/or other copyright owners and it is a condition of accessing publications that users recognise and abide by the legal requirements associated with these rights.

- Users may download and print one copy of any publication from the public portal for the purpose of private study or research.

- You may not further distribute the material or use it for any profit-making activity or commercial gain

- You may freely distribute the URL identifying the publication in the public portal.

If the publication is distributed under the terms of Article 25fa of the Dutch Copyright Act, indicated by the "Taverne" license above, please follow below link for the End User Agreement:

www.tue.nl/taverne

Take down policy

If you believe that this document breaches copyright please contact us at:

openaccess@tue.nl

providing details and we will investigate your claim. 


\title{
Electronic memory effects in diodes from a zinc oxide nanoparticle-polystyrene hybrid material
}

\author{
Frank Verbakel, Stefan C. J. Meskers, ${ }^{a)}$ and René A. J. Janssen \\ Molecular Materials and Nanosystems, Eindhoven University of Technology, P.O. Box 513, 5600 MB \\ Eindhoven, The Netherlands and Dutch Polymer Institute (DPI), P.O. Box 902, 5600 AX Eindhoven, \\ The Netherlands
}

(Received 17 March 2006; accepted 15 July 2006; published online 5 September 2006)

\begin{abstract}
Current-voltage characteristics of diode structures with an active layer of a zinc oxide nanoparticle-polystyrene hybrid material (1:2 by weight) deposited by spin coating from solution were investigated. Aluminum and poly(3,4-ethylenedioxythiophene):polystyrene-sulfonate were used as electrodes. After a forming step, the conduction under reversed bias voltage can be raised or lowered in a gradual and reversible manner by applying forward and reverse bias voltages, respectively. Electrically induced switching between states with high and lower conductivities is possible on a time scale of $100 \mathrm{~ms}$ and the conduction levels remain stable for over $1 \mathrm{~h}$. (C) 2006 American Institute of Physics. [DOI: 10.1063/1.2345612]
\end{abstract}

In recent years electronic memory effects in molecular materials have been investigated, in particular, field induced resistive switching in diodes. ${ }^{1,2}$ Also diodes with an active layer of molecular materials containing inorganic nanoparticles or metal interlayers have been investigated. ${ }^{3-5}$ In this work we study memory effects in the electrical conduction through an organic-inorganic hybrid layer consisting of zinc oxide nanoparticles mixed with polystyrene (PS) polymer. This mixture is solution processable and high loadings of $\mathrm{ZnO}$ particles can be achieved allowing for conduction of charge via interparticle contacts. $\mathrm{ZnO}$ was chosen because this material is known to exhibit memory effects in bulk conduction, ${ }^{6,7}$ an effect which is also known for many other metal oxides. ${ }^{8,9}$

Our diodes consist of a spin coated active layer between two electrodes (Fig. 1). The bottom electrode is tin-doped indium oxide with a spin coated film of poly(3,4ethylenedioxythiophene):polystyrene-sulfonate (PEDOT: PSS) of $0.7 \times 10^{2} \mathrm{~nm}$ thickness. The active layer is spin coated at $1500 \mathrm{rpm}$ from a solution containing $20 \mathrm{mg}$ PS $\left(M_{w}=250 \mathrm{~kg} / \mathrm{mol}\right.$, polydispersity index of 2.2) and $10 \mathrm{mg}$ of $\mathrm{ZnO}$ particles ${ }^{10}$ (diameter of $\sim 5 \mathrm{~nm}$ ) per milliliter of chloroform. This gives an active layer with a thickness of 4 $\times 10^{2} \mathrm{~nm}$. The top electrode is made by evaporation of aluminum. The active device area is $0.095 \mathrm{~cm}^{2}$. After deposition of $\mathrm{Al}$, the devices are stored and characterized in an inert atmosphere $\left(\mathrm{O}_{2}, \mathrm{H}_{2} \mathrm{O} \leqslant 1 \mathrm{ppm}\right)$.

The pristine devices have a current-voltage $(I-V)$ characteristic that shows considerable rectification when scanned between -2 and $+2 \mathrm{~V}$ (Fig. 1). Here, positive bias voltage refers to the PEDOT:PSS electrode being charged positive with respect to the $\mathrm{Al}$ electrode. The current density at $+2 \mathrm{~V}$ increases with the weight fraction of $\mathrm{ZnO}$ in the active layer. This indicates that the current is due to transport of electrons via a percolating network of inorganic particles in combination with a rectifying contact between the $\mathrm{ZnO}$ particles and the PEDOT:PSS and an Ohmic contact between $\mathrm{ZnO}$ and $\mathrm{Al}$. Extending the range of the bias voltage sweep from \pm 2 to $\pm 10 \mathrm{~V}$ introduces some hysteresis in the $I-V$, but the

\footnotetext{
${ }^{a)}$ Electronic mail: s.c.j.meskers@tue.nl
}

diode behavior is largely retained. After further stressing the device by applying $\mathrm{a}+15 \mathrm{~V}$ bias for $10 \mathrm{~s}$, the conduction increases further and becomes almost Ohmic. After this forming step, the $I-V$ characteristic shows considerable hysteresis for negative bias voltages when performing a cyclic $I-V$ scan. The voltage required for the forming step increases with decreasing $\mathrm{ZnO}$ content and devices with only PS do not show any forming at all when applying $+20 \mathrm{~V}$ for $30 \mathrm{~s}$.

The hysteresis shown by the formed device implies that its resistance can be altered in a reversible manner by apply-
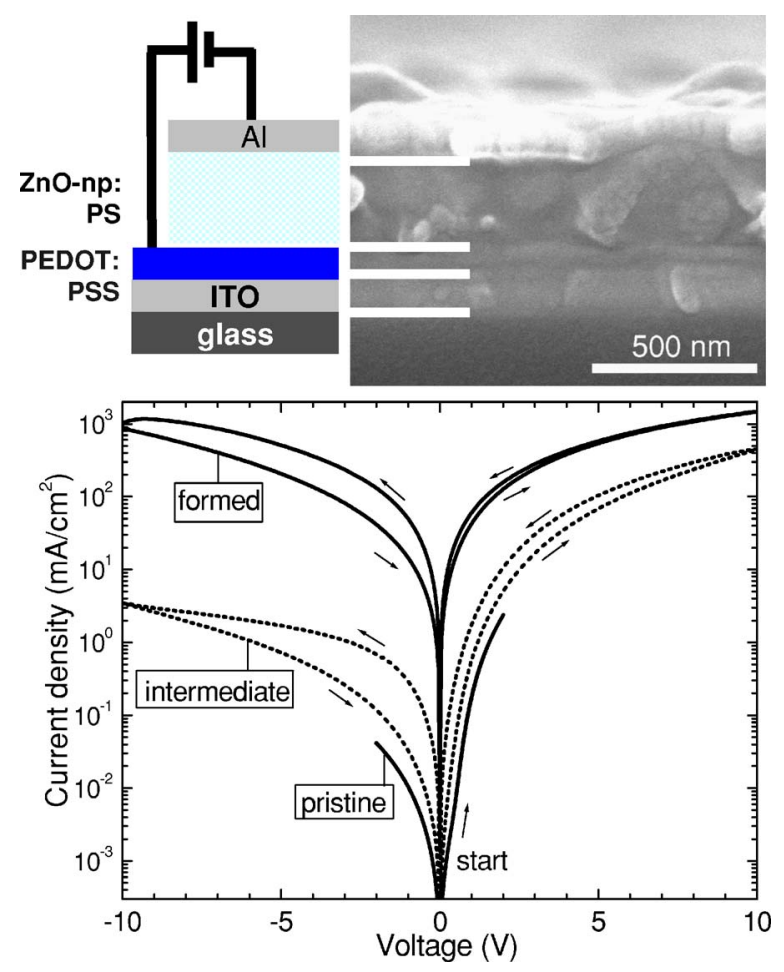

FIG. 1. (Top) Schematic representation of the device structure and crosssectional SEM image (ZnO:PS 1:2 by weight). (Bottom) $I-V$ characteristic of the diode in the pristine state and in an intermediate conduction state reached by scanning the bias voltage from $0 \mathrm{~V} \rightarrow+10 \mathrm{~V} \rightarrow-10 \mathrm{~V} \rightarrow 0 \mathrm{~V}$. The uppermost curve shows the $I-V$ after forming for $10 \mathrm{~s}$ at $+15 \mathrm{~V}$ bias voltage. Scan speed of $170 \mathrm{mV} / \mathrm{s}$. 


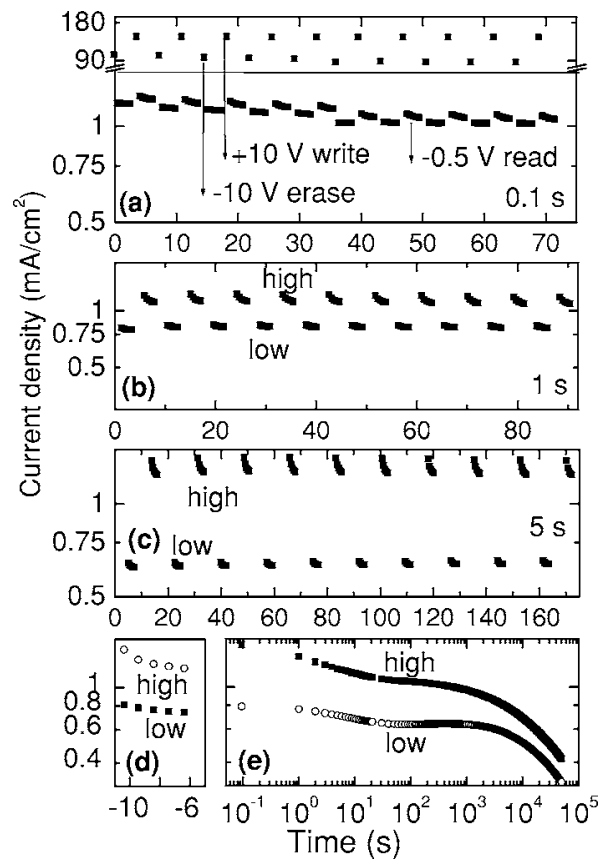

FIG. 2. [(a)-(c)] Current density of the ZnO:PS (1:2 by weight) device upon application of a cycle of voltage pulses: a $-10 \mathrm{~V}$ (erase), five $-0.5 \mathrm{~V}$ (read) pulses, a $+10 \mathrm{~V}$ (write), and five $-0.5 \mathrm{~V}$ (read) pulses. Duration of the $-0.5 \mathrm{~V}$ pulses is $0.1 \mathrm{~s}$. Duration of the +10 and $-10 \mathrm{~V}$ pulses is varied from 0.1 (a), 1 (b), to $5 \mathrm{~s} \mathrm{(c).} \mathrm{In} \mathrm{between} \mathrm{the} \mathrm{pulses} \mathrm{the} \mathrm{device} \mathrm{is} \mathrm{kept} \mathrm{at} \mathrm{zero} \mathrm{bias}$ voltage. [(d) and (e)] Preparation of the high and low conduction levels by application of a $+10 \mathrm{~V}(-10 \mathrm{~V})$ pulse for $5 \mathrm{~s}$. The current densities upon application of $-0.5 \mathrm{~V}, 0.1 \mathrm{~s}$ pulses are shown (d). Subsequently, a $-10 \mathrm{~V}$ $(+10 \mathrm{~V}), 5 \mathrm{~s}$ pulse is applied to switch from high to low conductivity (or vice versa) and the time evolution of the conductivity is probed, applying $-0.5 \mathrm{~V}, 0.1 \mathrm{~s}$ pulses (e).

ing voltage pulses. Applying a $+10 \mathrm{~V}$ pulse with a duration of either $0.1,1$, or $5 \mathrm{~s}$ to the diode, we find that the conduction level can be raised while an ensuing $-10 \mathrm{~V}$ pulse with the same temporal width reduces the conductivity again [Figs. 2(a)-2(c)]. These high and low conduction states correspond to the two branches of the $I-V$ curve of the formed device as shown in Fig. 1. In between these "write" and "erase" pulses, the conductivity is probed by measuring the current under application of a series of short $-0.5 \mathrm{~V}$ "read" pulses. During the time between the pulses, the device is kept at zero bias. This cycle can be repeated many times. As can be seen in Fig. 2, the ratio between the high and low conduction levels (as probed at $-0.5 \mathrm{~V}$ ) increases with the duration of the $\pm 10 \mathrm{~V}$ pulses and reaches a factor of 2 for pulses of $5 \mathrm{~s}$. The stability of the high and low conduction levels in time has been evaluated [Figs. 2(d) and 2(e)]. In order to monitor the preparation of the high conduction state, the device is first brought to the low conduction state and probed [Fig. 2(d)]. Subsequently, the high conduction state is prepared by applying $+10 \mathrm{~V}$ bias for $5 \mathrm{~s}$ and the time evolution of the conduction is then probed in the $1-10^{5} \mathrm{~s}$ interval by applying a series of $-0.5 \mathrm{~V}, 0.1 \mathrm{~s}$ pulses [Fig. 2(e)]. In the first seconds after the $+10 \mathrm{~V}$ pulse, the conduction shows some decay, but in the 10-1000 s time window the level does not show any substantial change. The time evolution of the low conductivity state is probed in similar manner and shows some rapid initial decay after the $-10 \mathrm{~V}$ pulse, remaining relatively stable up to $1000 \mathrm{~s}$. On the time scale of several hours, both the high and low conduction levels deDownloaded 09 May 2008 to 131.155.151.52. Redistribution subject

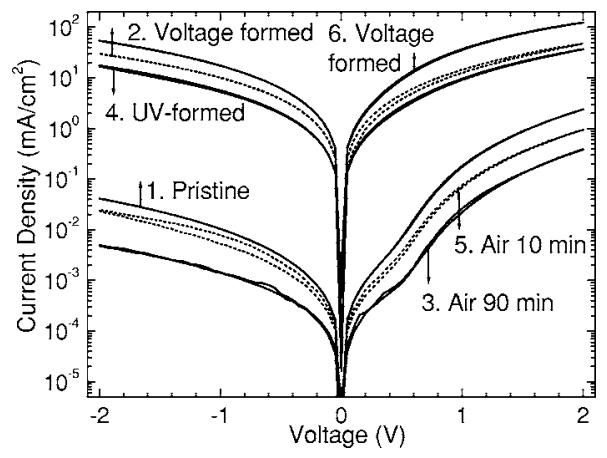

FIG. 3. $I-V$ characteristics of a $\mathrm{ZnO}: \mathrm{PS}$ (1:2 by weight) device in chronological order: (1) pristine device, (2) after forming at $+15 \mathrm{~V}$ bias voltage for $5 \mathrm{~s}$, (3) after subsequent exposure to air for $90 \mathrm{~min}$, (4) after illumination for 5 min with $80 \mathrm{~mW} / \mathrm{cm}^{2}$ light intensity from a tungsten halogen source, (5) exposure to air (10 $\mathrm{min})$, and (6) after bias stress at a voltage of $+10 \mathrm{~V}$ for $30 \mathrm{~s}$.

crease but are still much higher than the conduction level in the pristine device.

The forming process and the associated memory effects may arise from modulation of the density of mobile electrons in the $\mathrm{ZnO}$ particles. For bulk $\mathrm{ZnO}$, unintentional $n$-type doping is well known and is usually ascribed to native point defects such as oxygen vacancies and/or interstitial $\mathrm{Zn}$ atoms. $^{11,12}$ In addition, a number of extrinsic dopants are known (including $\mathrm{Al}$ and $\mathrm{H}$ ). Further information on the forming process comes from experiments on the influence of molecular oxygen and ultraviolet (UV) illumination on the conduction (Fig. 3). When the device is exposed to air after the formation step, the Ohmic conduction is strongly suppressed and the initial diodelike characteristic is restored. Subsequent illumination with UV light results in Ohmic conduction, which can be quenched again by exposure to air. This effect of UV light is also observed for pristine films. After this UV treatment and $\mathrm{O}_{2}$ exposure, the films can be formed again by application of a positive bias voltage. Thus the effects of UV illumination and positive bias stress on the conductivity seem indistinguishable.

In the case of UV illumination, the metastable conductivity is likely to be induced by either photogenerated electrons or holes in the $\mathrm{ZnO}$ (persistent photoconductivity). In order to distinguish between the two types of carriers, we have mixed $\mathrm{ZnO}$ nanoparticles with regioregular poly(3hexylthiophene) (P3HT) polymer (purchased from Rieke Metals Inc.). Also for this hybrid material, electronic memory effects can be observed after an initial forming. In this case illumination with visible light results in photoexcitation of the polymer and subsequently leads to charge generation at the $\mathrm{ZnO}: \mathrm{P} 3 \mathrm{HT}$ interface with the electrons residing on the $\mathrm{ZnO}$ nanoparticle. ${ }^{13}$ Curiously, illumination with visible light $(\lambda>420 \mathrm{~nm})$ does not enhance the dark conduction level after prolonged irradiation while UV irradiation $(\lambda$ $<420 \mathrm{~nm}$ ) of the same film indeed results in Ohmic conduction. Apparently the $n$-type doping is induced by the presence of photogenerated holes in the $\mathrm{ZnO}$ nanocrystal.

This behavior is completely in line with earlier studies on persistent photoconductivity in porous, bulk $\mathrm{ZnO}$ (Refs. 14-17) and ZnO nanostructures ${ }^{18-23}$ where it was shown that photogenerated holes induce desorption of oxygen absorbed on the surface. Adsorbed oxygen acts as an electron trap and its release enhances the concentration of mobile electrons to AIP license or copyright; see http://apl.aip.org/apl/copyright.jsp 


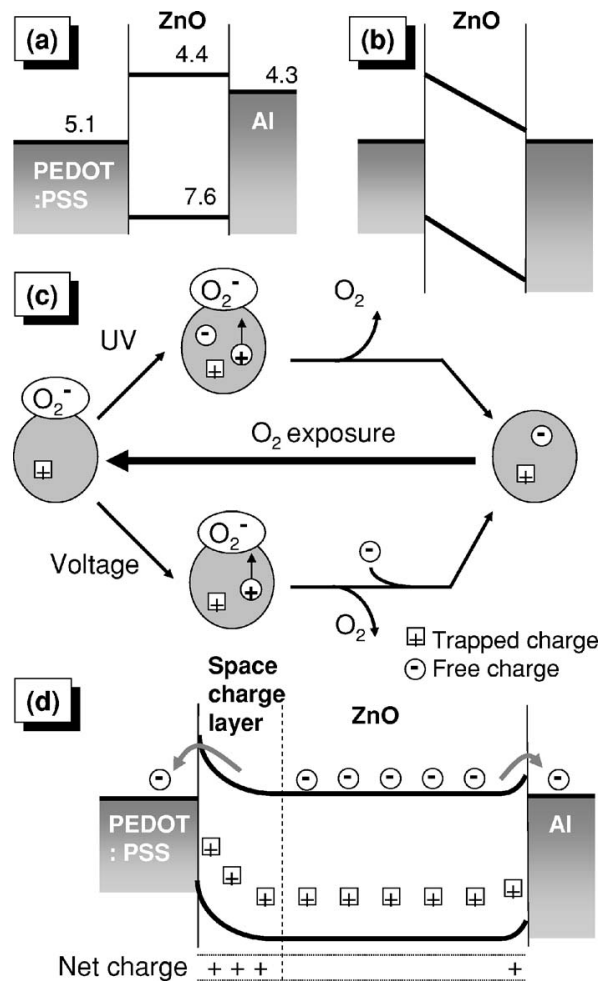

FIG. 4. [(a) and (b)] Band level diagrams for pristine device illustrating the rectifying PEDOT:PSS/ZnO contact. (c) Schematic representation of the UV light and bias voltage induced changes in the $\mathrm{ZnO}$ particles. An injected or photogenerated hole induces desorption of oxygen. This results in a very thin space charge layer in the formed device (d) which lowers the barrier for electron injection via the PEDOT:PSS contact.

originating from the native doping and photoexcitation of the $\mathrm{ZnO}$. Since UV illumination and voltage stress give rise to the same conduction levels, we argue that the forming process observed under forward bias stress results from holes injected via the PEDOT:PSS contact [Fig. 4(c)]. In agreement with this, we find that the forming process is only induced by applying a large positive bias voltage and does not occur under reverse bias conditions where the injection barrier for holes into $\mathrm{ZnO}$ is much larger [Figs. 4(a) and 4(b)]. After forming, the density of free electrons in $\mathrm{ZnO}$ is increased, explaining the significant increase in conductivity [Fig. 4(d)]. Near the PEDOT:PSS electrode, diffusion of these free electrons will result in a narrow depletion zone, causing a strong band bending that facilitates electron injection from PEDOT:PSS into $\mathrm{ZnO}$ under reverse bias. Because the current under reverse bias is now controlled by a very thin interface region, small changes near the contact such as a reversible electrochemical doping of the $\mathrm{ZnO}$ particle near the PEDOT:PSS interface may explain the memory effects observed. Possible electrochemical processes involve chemisorbed/physisorbed oxygen and small mobile ions $\left(\mathrm{H}^{+}\right.$ and $\mathrm{Na}^{+}$) originating from the PEDOT:PSS. Reversible switching is not observed for devices without the PEDOT:PSS layer.

In conclusion, a reversible electronic memory effect has been observed in diode structures with a spin coated hybrid layer comprising $\mathrm{ZnO}$ nanoparticles. This memory effect is observed after a forming step. The forming process itself is interpreted in terms of desorption of oxygen from the $\mathrm{ZnO}$ nanoparticle surface induced by injection of holes via the PEDOT:PSS contact, leading to a higher $n$-type conductivity via interparticle $\mathrm{ZnO}$ contacts. The electronic memory effects are attributed to a reversible electrochemical process at the $\mathrm{ZnO} / \mathrm{PEDOT}$ :PSS interface.

The authors thank W. J. E Beek for valuable discussions and C. van Heesch for SEM measurements. The work of one of the authors (F.V.) forms part of the research program of the Dutch Polymer Institute (DPI), Project DPI No. 523.

${ }^{1}$ Y. Yang, L. Ma, and J. Wu, MRS Bull. 29, 833 (2004).

${ }^{2}$ J. C. Scott, Science 304, 62 (2004).

${ }^{3}$ Y. Yang, J. Ouyang, L. Ma, R. J.-H. Tseng, and C.-W. Chu, Adv. Funct. Mater. 16, 1001 (2006).

${ }^{4}$ L. D. Bozano, B. W. Kean, M. Beinhoff, K. R. Carter, P. M. Rice, and J. C. Scott, Adv. Funct. Mater. 15, 1933 (2005).

${ }^{5}$ W. Tang, H. Z. Shi, G. Xu, B. S. Ong, Z. D. Popovic, J. C. Deng, J. Zhao, and G. H. Rao, Adv. Mater. (Weinheim, Ger.) 17, 2307 (2005).

${ }^{6}$ T. Hada, K. Wasa, and S. Hayakawa, Jpn. J. Appl. Phys. 10, 521 (1971).

${ }^{7}$ O. Hunter, Jr. and J. A. Schaefer, U.S. Patent 4,472,296 (18 September 1989).

${ }^{8}$ G. Dearnaley, A. M. Stoneham, and D. V. Morgan, Rep. Prog. Phys. 33, 1129 (1970)

${ }^{9}$ R. E. Thurstans and D. P. Oxley, J. Phys. D 35, 802 (2002).

${ }^{10}$ W. J. E. Beek, M. M. Wienk, M. Kemerink, X. Yang, and R. A. J. Janssen, J. Phys. Chem. B 109, 9505 (2005).

${ }^{11}$ S. J. Pearton, D. P. Norton, K. Ip, Y. W. Heo, and T. Steiner, J. Vac. Sci. Technol. B 22, 932 (2004).

${ }^{12}$ Ü. Özgür, Ya. I. Alivov, C. Liu, A. Teke, M. A. Reshchikov, S. Doğan, V. Avrutin, S.-J. Cho, and H. Morkoç, J. Appl. Phys. 98, 41301 (2005).

${ }^{13}$ W. J. E. Beek, M. M. Wienk, and R. A. J. Janssen, Adv. Funct. Mater. 16, 1112 (2006).

${ }^{14}$ D. A. Melnick, J. Chem. Phys. 26, 1136 (1957).

${ }^{15}$ R. J. Collins and D. G. Thomas, Phys. Rev. 112, 388 (1958).

${ }^{16}$ R. Ghosh, B. Mallik, and D. Basak, Appl. Phys. A: Mater. Sci. Process. 81, 1281 (2005)

${ }^{17}$ S. A. Studenikin, N. Golego, and M. Cocivera, J. Appl. Phys. 87, 2413 (2000).

${ }^{18}$ M. Haase, H. Weller, and A. Henglein, J. Phys. Chem. 92, 482 (1988).

${ }^{19}$ Q. H. Li, T. Gao, Y. G. Wang, and T. H. Wang, Appl. Phys. Lett. 86, 123117 (2005).

${ }^{20}$ K. Keem, H. Kim, G.-T. Kim, J. S. Lee, B. Min, K. Cho, M.-Y. Sung, and S. Kim, Appl. Phys. Lett. 84, 4376 (2004).

${ }^{21}$ M. S. Arnold, Ph. Avouris, Z. W. Pan, and Z. L. Wang, J. Phys. Chem. B 107, 659 (2003).

${ }^{22}$ S. E. Ahn, J. S. Lee, H. Kim, S. Kim, B. H. Kang, K. H. Kim, and G. T. Kim, Appl. Phys. Lett. 84, 5022 (2004).

${ }^{23}$ H. Kind, H. Yan, B. Messer, M. Law, and P. Yang, Adv. Mater. (Weinheim, Ger.) 14, 158 (2002). 